\title{
ICT4D \& THE SUSTAINABLE DEVELOPMENT GOALS
}

\author{
Franz Ferdinand Rothe \\ Vrije Universiteit Brussel, imec-SMIT, Pleinlaan 9, 1050 Brussels, Belgium
}

\begin{abstract}
The field of ICT4D (ICT for Development) entails using ICTs in support of the international development agenda, such as efforts against poverty or for better education in developing countries. The conceptualisation of ICT4D strongly depends on what is understood as international development itself. Hence, this paper argues that the introduction of the United Nations' Sustainable Development Goals (SDGs) in 2015 can be understood as a caesura not only for conceptualising development, but, in turn, for conceptualising ICT4D, as well. On the basis of literature review, this paper analyses the SDG framework and applies it to theories of ICT4D, outlining to which extent this new development agenda requires new approaches to ICT4D. In doing so, this article aims to sensitise the reader towards the challenges and potential dilemmas emerging from this transition and to spark debate on how to conceptualise ICT4D in response.
\end{abstract}

\section{KEYWORDS}

ICT4D, Sustainable Development Goals, Policy Coherence

\section{INTRODUCTION}

The field of ICT4D (Information and Communication Technologies for Development) is driven by the conviction that ICTs can support efforts of international development ${ }^{1}$, such as the fight against poverty, for better education or reduced inequalities. Over the past decades, the notion of ICT4D has evolved alongside the shifting paradigms of development itself (Zheng et al., 2017). Having advanced from a modernist focus on North-South ICT transfer for economic growth, ICT4D has been attributed increasingly multi-dimensional potential, as the international community has embraced concepts such as human or sustainable development (Heeks, 2009; Thapa and Sæbø, 2014). Coming from the early enthusiasm around, for example, colourful laptops that promised to automatically modernise not only the African classrooms but also the continent's economies and societies, scholars have reached the more nuanced conception that ICTs are only as valuable (or harmful) for development, as the interventions in which they are embedded.

Given that what we mean by ICT4D thus depends on what we mean by development, this paper argues that the introduction of the United Nations' Sustainable Development Goals (SDGs) in 2015, which mark a caesura for conceptualising development, should in turn be seen as a caesura for conceptualising ICT4D as well. However, research and guidance regarding the implications of this new development agenda for using ICTs for development is scarce. This paper responds to this gap, by translating the SDG framework onto the field of ICT4D. On the basis of a literature review, this paper analyses the SDG framework and applies it to theories of ICT4D, outlining the implications of transitioning to the post-2015 concept of sustainable development. In doing so, this paper aims to sensitise the reader towards the challenges and potential dilemmas emerging from this transition, and to spark debate on how to conceptualise ICT4D in response.

\footnotetext{
${ }^{1}$ As opposed to its definition in the field of IT, the term development will be used according to its definition in international development studies, describing socio-economic advances in so-called developing countries and beyond.
} 


\section{WHAT IS NEW ABOUT THE SDGs?}

ICT4D can be defined as "technology [being] used to help deliver on the international development agenda" (Heeks, 2018, p. 18). Defining the international development agenda is thus integral to conceptualising ICT4D. When the SDGs were adopted with the 2030 Agenda for Sustainable Development in September 2015, the set of 17 goals encompassing 169 targets were the outcome of several years of consultations with governments, international organisations, the private sector, academia, and civil society. Therefore, the SDG agenda, while not being uncontested, arguably comes closest to representing a shared agenda for international development.

In order to assess what this new agenda means for ICT4D, we must consider the novel nature of the SDGs, in contrast to their predecessors such as the Millennium Development Goals (MDGs), the agenda that guided development efforts from 2000 until 2015. As LeBlanc (2015) synopsises, "[t]he novelty of the SDGs $[\ldots]$ is that they aim to cover the whole sustainable development universe, which includes basically all areas of the human enterprise on earth" (p. 11). In comparison to the earlier agenda, the UN (2015) resolution on the SDGs defines an agenda of goals and targets that are universal, global and integrated.

These notions represent three novel characteristics of the SDGs, which are (1) the holistic scope of targets, (2) their applicability for all countries alike, and (3) their essential interconnectedness and interdependence. While the former of these aspects has been subject to research from many sides, the latter two shall be central to the remainder of the paper. Focusing on the implications for ICT4D, section 3 will demonstrate the link between (1) the topical and (2) the geographical conceptual expansion before we discuss their implications for (3) policy coherence in Section 4.

\section{ICT4D \& UNIVERSALITY}

First and foremost, as compared to the 8 MDGs, the SDGs cover a much larger scope of development objectives with 17 goals and 169 associated targets. This large amount of new goals, covering areas across the social, environmental and economic dimensions of sustainable development, can be understood as new opportunities for ICTs to play a role in international development. While ICTs are featured surprisingly little in the SDGs, being mentioned in merely 4 of the 196 targets, they are recognised as integral drivers for sustainable development and a significant amount of research has been produced to make the implicit potentials of ICT to support the SDGs explicit (NetHope 2015; Ericsson 2015; ITU 2016).

However, to conclude that the widening scope of goals merely suggests a widening playing field for post-2015 ICT4D would be a short-sighted assumption. In fact, the holistic architecture of the SDGs goes far beyond these new topical areas. As the following paragraphs will demonstrate, it also widens the horizon of development in a geographical sense.

\subsection{ICT 4 Global Development}

As opposed to the MDGs, the SDGs acknowledge sustainable development as a global challenge, being "universal goals and targets which involve the entire world, developed and developing countries alike" (United Nations 2015, para. 5). In fact, this is strongly linked to the broadened topical scope. The Global North might be more developed with regard to traditional development issues such as absolute poverty or health, which were at the core of the MDGs. Areas such as climate change, sustainable production, or reducing inequalities, however, are as much a challenge for the Global North as they are for so-called developing countries (Bertelsmann Stiftung and SDNS, 2016).

In the words of Jeffrey Sachs, "[t]he United States, just like Mali, needs to learn to live sustainably. The rich countries like the poor have to promote more social inclusion, gender equality, and of course energy systems that are low carbon and resilient" (2015, p. 484). In a post-2015 world, there is hence no longer such a thing as a developed world. 


\section{2 'Everything' is ICT4D?}

This widened topical and geographic understanding of development leads to a number of potential dilemmas, when applied to ICT4D. Following the holistic and universal interpretation, ICT4D becomes a field going far beyond its traditional conception. To give an example, using big data to improve public transport in Brussels does, according to this definition, represent as much of an ICT4D intervention, as does a smart farming project in Burkina Faso.

On the one hand, this corresponds with the development challenges of our time. On the other hand, however, it might be understandable if ICT4D practitioners question the practicality of such a definition of their field. While the old and largely overcome understanding of ICT4D as merely fostering economic growth in the Global South is clearly misaligned and counterproductive to the global development efforts, taking the SDG narrative literally could arguably pose the risk of diluting the notion into a meaningless catch-all term. These two poles thus provide a spectrum, reaching from a clearly outdated development concept to an approach that might prove too idealistic to (yet) fully apply to ICT4D. This paper does not aim at providing an answer to this dilemma. Much rather it hopes to sensitise stakeholders towards this spectrum, along which ICT4D must consciously and rationally be situated.

\section{ICT4 INTEGRATED DEVELOPMENT}

As indicated in Section 3, a further defining novelty of the SDG architecture can be found in the "deep interconnections and many cross-cutting elements across the new Goals and targets" (United Nations, 2015, para. 17). The network character of the goals adds another crucial element of complexity. As the goals and targets are integrated and indivisible (United Nations, 2015), coherence must be ensured between all of the SDGs' 169 targets. The network architecture of the SDGs shall at this point briefly be outlined, before its implications for ICT4D are assessed.

\subsection{A Network of Goals}

In a Working Paper for the UN Department of Economic and Social Affairs, David Le Blanc (2015) analyses the manifold links between the 169 targets, which spin a complex network between the 17 goals, as most areas of sustainable development are featured not only in their specific goal, but are highlighted in the targets of other related goals as well. This network architecture responds to the fact that " $[\mathrm{t}]$ he interlinkages $[\ldots]$ of the Sustainable Development Goals are of crucial importance in ensuring that the purpose of the new Agenda is realized" (United Nations, 2015, p.4).

Acknowledging these interdependencies between the SDGs could "correct one of the drawbacks of the MDGs, in which 'silo' goals encouraged silo policies and did not make links and trade-offs across areas explicit” (Le Blanc, 2015, p. 11). Translating this post-silo architecture into development action that does take the whole of the SDG Agenda into account, will represent one of the biggest challenges for development practicioners, including and in particular for those working in ICT4D. As the following sections will demonstrate, this transition bears another potential dilemma for ICT4D, which should be debated within the community.

\subsection{Coherence for Sustainable Development}

On the one hand, the interconnectedness of goals indicates that an intervention in one of the areas of sustainable development can simultaneously support other goals as well. On the other hand, however, if the intervention is not coherent with the entirety of the SDG framework, its effects can undermine other objectives of the agenda. Policy coherence between the various actions taken within the development sector thus represents a multi-directional challenge. If actors in certain areas of sustainable development disregard their potential effect on other goals, their interventions risk doing more damage than good. Without internal coherence, it will thus be impossible to deliver on the SDGs as a whole. 
The SDGs therefore bring forward the concept of PCSD, which urges development actors to strive for coherence within and between the various areas of development cooperation and take into account their potential (side-)effect on other goals, to avoid that their interventions do more damage than good. Finding synergies - or, at least, preventing negative side-effects - hence presents a central challenge for ICT4D in post-2015 development.

\subsection{SDGs as a Deadlock for ICT4D?}

The idea that measures to support one aspect of development should not undermine the rest of the international development goals may appear self-evident and rather straightforward. On a closer look, however, the multi-directionality of coherence required for sustainable development oftentimes makes this a highly complex challenge. Obviously, this challenge is not exclusive to the field of ICT4D but an issue for everybody working in international development. Yet, the multi-dimensional externalities associated with ICTs make the matter of coherence particularly relevant and challenging when utilizing them in a development context. ICT4D projects are likely to have (side-)effects on the three pillars of the SDGs, since the use of ICTs affects environmental, social and economic matters. The economic footprint of the ICTs, the labour conditions in their production and the inequalities that can arise from digitally including some and excluding others are merely a few of these inherent detriments. When using ICTs to support a particular development goal, their potential positive impact is thus bound to come at a certain developmental price.

For ICT4D, this holistic conception of development thus reveals another dilemma. Should projects be abandoned if they are incoherent with other goals? Clearly, if ICT4D projects contribute to environmental pollution or child labour, they can hardly be called 4D. In practice, however, it becomes obvious that a radical interpretation of these claims could put ICT4D, and arguably most other development sectors, into a deadlock. Considering the wide scope of externalities that are related to ICTs, it is nearly impossible to practice ICT4D without negative development effects. This begs the question, where a line should be drawn to avoid putting ICT4D in a deadlock? When is a project's positive impact in its target area outweighed by its negative side-effects on others? Surely, there will not be a one-size-fits-all answer to this dilemma. Yet, it must be discussed how ICT4D actors can guarantee that these side-effects are being thoroughly and transparently assessed.

\section{CONCLUSION}

The introduction of the SDGs marked a caesura for conceptualising development. In turn, it must be understood as caesura for conceptualising ICT4D as well. As this paper demonstrated, applying the new principles at the core of the SDGs onto the field of ICT4D requires us to fundamentally rethink certain aspects of ICT4D. If we are serious about using ICTs in support of this new agenda, we cannot stop at the comfortable task of embracing its new topical scope. Much rather, we must equally open the Pandora's Box of considering the complexity that results from this transition.

Should ICT4D open up to the Global North, as development is no longer an exclusive challenge for the Global South? How close can ICT4D come to meeting the holistic and integrated SDG approach without becoming an unworkable utopia? How far can it afford to stay behind without failing or even undermining the SDGs by doing more damage than good? And how can practitioners, to whom these questions might not seem pressing or even relevant, be incentivised to acknowledge that sometimes no ICT4D project is the better choice for sustainable development? By outlining this scope of challenges that a serious integration of SDG principles in the field of ICT4D would entail, this paper hopes to spark a meaningful debate around the future of ICT4D. 


\section{REFERENCES}

Bertelsmann Stiftung and SDNS (2016) SDG Index \& Dashboards: A Global Report. Bertelsmann Stiftung.

Ericsson (2015) 'ICT \& SDG - How Information and Communications Technologies can Achieve the Sustainable Development Goals.' Ericsson in collaboration with Earth Institute at Columbia University.

Heeks, R. (2009) The ICT4D 2.0 manifesto where next for ICTs and international development? Manchester: University of Manchester. Institute for development policy and management (IDPM). Development informatics group.

Heeks, R. (2018) Information and communication technology for development (ICT4D). New York: Routledge. Available at: http://search.ebscohost.com/login.aspx?direct=true \&scope $=$ site $\& d b=n l e b k \& d b=n l a b k \& A N=1554067$ (Accessed: 18 January 2018).

ITU (2016) Advancing Sustainable Development Through Information and Communication Technologies: WSIS Action Lines Enabling SDGs. Geneva: ITU.

Le Blanc, D. (2015) 'Towards integration at last? The sustainable development goals as a network of targets', Sustainable Development, 23(3), pp. 176-187.

Mackie, J., Ronceray, M. and Spierings, E. (2017) Policy coherence and the 2030 Agenda: Building on the PCD experience. Maastricht: ECDPM.

Malone, D. and O'Dwyer, K. J. (2014) 'Bitcoin Mining and its Energy Footprint', in. Institution of Engineering and Technology, pp. 280-285. doi: 10.1049/cp.2014.0699.

NetHope (2015) SDG ICT Playbook - From Innovation to Impact. Fairfax (VA): NetHope.

Nilsson, M., Griggs, D. and Visbeck, M. (2016) 'Map the interactions between Sustainable Development Goals', Nature, 534, pp. 320-323.

Sachs, J. D. (2015) The Age of Sustainable Development. Columbia University Press.

Thapa, D. and Sæbø, Ø. (2014) 'Exploring the link between ICT and development in the context of developing countries: a literature review', The Electronic Journal of Information Systems in Developing Countries, 64.

United Nations, G. A. (2015) Transforming our world: the 2030 agenda for sustainable development (A/RES/70/1). New York: United Nations.

Zheng, Y. et al. (2017) 'Conceptualizing development in information and communication technology for development (ICT4D)', Information Technology for Development, pp. 1-14. doi: 10.1080/02681102.2017.1396020. 